\title{
Water Safety Practices and Occurrence of Diarrhea Among Children Under Five in Different Households of Njemp Community, Baringo County, Kenya
}

\author{
Phyllis Waruguru $^{1 *} \quad$ Peter M. Chege ${ }^{2}$ \\ 1.Department of Food Science, Nutrition and Technology, University of Nairobi, Kenya - P.O Box 30197-00100 \\ Nairobi, Kenya \\ 2.Department of Food, Nutrition and Dietetics, Kenyatta University, Kenya - P.O Box 43844-00100 Nairobi,
} Kenya

\begin{abstract}
Water safety and quality is a key component in public health. Despite substantial progress made during the last decades, $11 \%$ of the global population are still not accessing adequate clean water and only $64 \%$ are able to access improved sanitation. Household water treatment methods, such as boiling or chlorination, have long been recommended in developing countries. Diarrhea diseases cause major public health problem in children underfive years of age, in addition, Water safety practices has been shown to affect health status. More research has focused on information about water safety practices at household level with minimal information on the relationship between water safety practices and occurrence of diarrhea among children below 5 years. This study was carried out to outline the occurrence of childhood diarrhea in relation to water safety practices. The study adopted a cross-sectional study design. This was among Njemp community in Baringo County, Kenya. Assessed was the household socio-demographic characteristics, sources of water, methods of domestic water treatment and the prevalence of diarrhea. Four hundred and twenty-two (422) households were targeted. However, data is reported for 401 households. Data was collected using a semi-structured questionnaire also the laboratory water analysis from different sources and treatment methods was done to determine the level of $E$. coli. Analysis was carried out using SPSS software. Chi-square was used for categorical variables while Pearson's correlation coefficient was used for non-categorical variables to show the association between water safety practices and occurrence of diarrhea. Results show that majority of mothers $(50.6 \%)$ were of age $26-35$ years and married (78.3\%). There was no significant difference in the mother's various ages. The study also notes that most of the respondents $(46.9 \%)$ had education up to primary level. Findings from household income indicates that majority of households earned less than Ksh. 10,000. River was the main source of water $(50.6 \%)$. A few $(31.2 \%$ and $18.2 \%)$ used borehole and rainwater respectively. The study found that river was the most contaminated source of water (50 MPN/100 mL) which was unsafe for human consumption according to WHO classification. On water treatment, majority (37.2\%) used Moringa oleifera seeds for water treatment which acts as a natural absorbent and antimicrobial agent. $20.9 \%$ did not treat their water. The prevalence of diarrheal was $57.6 \%$. There was a significant relationship between the water safety practices and occurrence of diarrhea. This study concludes that water safety practices of the Njemp community was low and as thus led to increased occurrence of diarrhea. This study recommends to the County Government of Baringo to come up with a centralized water treatment plant or dig boreholes and supply water to the people in Baringo County.
\end{abstract}

Keywords: Water Safety, Diarrhea, children under 5 years

DOI: $10.7176 /$ FSQM/92-06

Publication date: December $31^{\text {st }} 2019$

\section{Introduction}

Water safety and quality is a key component in public health, fundamental to human development and wellbeing. Providing access to safe water is one of the most effective ways in promoting health and reducing poverty. Globally, an estimated 633 million people lack access to safe water sources, 319 million of whom live in subSaharan Africa, and 2.4 billion of whom do not use improved sanitation, as defined by the WHO/UNICEF Joint Monitoring Programme (WHO, 2015). Despite substantial progress made during the last decades, $11 \%$ of the global population are still not drinking improved water and only $64 \%$ are able to access improved sanitation (WHO 2000). The Joint Monitoring Program of the World Health Organization and United Nations defines improved drinking water simply according to source type, which includes: a piped connection into the home, public taps or standpipes, tube wells or boreholes, protected dug wells, protected springs, and rainwater collection (United Nations 2012). These source selections are intended to protect drinking water by the nature of their construction, this definition does not directly address finished water quality, and therefore has the capacity to misrepresent the number of people with access to safe drinking water (UNICEF \& WHO 2013; Baum et al. 2014). Owing to a number of factors including time, funding, treatment intervention, cultural practices, and laboratory or field technological limitations, it is difficult to define a standard protocol of methodological 
approaches for evaluating water and sanitation interventions in developing countries. Effectiveness studies traditionally utilize engineering and water quality indicators (Lee \& Schwab 2005; Duke et al. 2006; Sobsey et al. 2008), health epidemiological information (Reller et al., 2003; Clasen et al. 2007), household and community attributes gathered through social science methodology (Prokopy et al. 2008; Whittington et al. 2009; Peter \& Nkambule 2012), or combinations of the three. Most of these effectiveness studies focus on one specific intervention or one implementation protocol and do not evaluate safe water access within a region as a whole. This article, presents a summary of viable Escherichia coli concentration measurements for drinking water samples from different water sources and treatment in Njemp Community households of Baringo County. We sought to evaluate $E$. coli concentrations for samples collected from different water sources before and after treatment. For river the $E$. coli concentration was $50 \mathrm{MPN} / 100 \mathrm{~mL}$, borehole $9 \mathrm{MPN} / 100 \mathrm{~mL}$ and rain water $5 \mathrm{MPN} / 100 \mathrm{~mL}$.

Boiling, disinfecting, and filtering water within the home can improve the microbiological quality of drinking water among the hundreds of millions of people who rely on unsafe water supplies. However, the impact of these interventions on diarrhea is unclear. Most studies using open trial designs have reported a protective effect on diarrhea while blinded studies of household water treatment in low-income settings have found no such effect. However, none of those studies were powered to detect an impact among children under five and participants were followed-up over short periods of time. The aim of this study was to measure the effect of in-home water disinfection on diarrhea among children under five.

Diarrhea is the main killer of children, estimated to have killed 558,000 children aged 1-59 months in 2013. (Liu L. et al 2013). A prevalence of 50.9\% of children in Baringo County has parasitic infection and $17 \%$ have diarrhea occurrence of more than 5 episodes in a year. The primary causes of many childhood illnesses and poor health in Kenya, are water-related (Sharma et al.1996) Amongst these illnesses, diarrhea remains one of the most important environmental health problems in developing countries. According to the most recent Global Water Supply and Sanitation Assessment (WHO/UNICEF 2000), there are four billion cases of diarrhea each year with 2.2 million deaths, most of which occur in children under the age of five. In order to address this and other environmental health issues, the 1990 World Summit for children set a global goal for the provision of universal access to safe drinking water and sanitary conditions by the year 2000 (Bellamy 2000).

Children under five years are more vulnerable to infection because of their less developed immune system and reduced self-care. As such, infections results to poor health and malnutrition. To minimize diarrhea among children below five years, information specific to water safety practices at household level is needed. Most studies shows information about water safety practices at household level with minimal information on the relationship between water safety practices and occurrence of diarrhea. Studies focusing on children under five years and occurrence of diarrhea have been scarce in Kenya. Thus, minimal information exists on how to design programs to intervene on this vulnerable group. This is more so in rural and Pastoralists communities. The population in Baringo County is vulnerable to water safety due to low rainfall and due to limited health facilities. This study thus assessed the relationship between water safety practices and occurrence of diarrhea among children below 5 years in Baringo County.

This study focused to assess the prevalence of childhood diarrhea in relation to water safety practices. It also determined the socio-demographic characteristics of the households and laboratory analyses of the microbial quality of drinking water.

In the manufacturing sector today, human capital is still essential for most factories to carry out a variety of manual operations, in spite of the rapid advancement of automation technology and robotics. Futuristic vision of "unmanned manufacturing" (Deen 1993) is forbiddingly expensive, because all its hardware components need to be computer controlled so as to freely communicate with each other; and yet, most of the outcomes are not promising (Sun \& Venuvinod 2001). By and large, factories equipped with relatively simple machinery controls will require continuous attendance of human operators; for examples, textile mills, leather products, and medical appliances. With limited capital investments in production equipment, the main budget of their fixed costs lies on the workforce size (Techawiboonwong et al. 2006).

With regard to cost-effectiveness, labour planning always opts for the minimum amount of workers needed to deal with the daily operations, as well as the probable rate of disturbance (Lim et al. 2008). The workforce disturbance is often ascribed to absenteeism and turnover, which may result in considerable loss of productivity for any labour-intensive division (Easton \& Goodale 2002). Buffering with redundant skilled workers (Molleman \& Slomp 1999) or relief workers (Redding 2004) might be a direct solution to absenteeism; however, the rising labour cost must be justifiable due to the fact that underutilisation of labour during low demand seasons is considered a waste of resources. Absenteeism is the measure of unplanned absences from workplace due to some reasons like personal emergency, accident, illness, etc. Turnover occurs when an active worker resigns from the company of his own accord, thus leaving a vacant post until a replacement is found. If such disturbance has caused a large number of tasks become unattended and overdue, the company is then vulnerable to overtime cost, shrunk capacity and productivity, extra queuing time, lost business income, etc. In order to 
prevent these deteriorative effects, optimising the number of workers can be helpful. As a fundamental branch of knowledge in manufacturing business, workforce management will never fall behind the times. Therefore, it is worth an attempt to incorporate a novel methodology, such as HMS, into the state of the art of workforce sizing.

\section{Materials and methods}

The study adopted a cross-sectional study design. A survey was carried among the Njemp community and focused on, socio-demographic characteristics, water sources, water treatment and prevalence of childhood diarrhea.

The study was conducted in Marigat Division, Central Baringo sub-county in Baringo County with an altitude of $1000 \mathrm{~m}$ above sea level. The poverty levels stand at 58.5\% with a dependency ratio of 100:107. The major livelihood activity is Semi-nomadic livestock rearing, though there is an increasing interest in crop production to augment the family food supply. The rangelands on which the livestock and the community depend are denuded and seriously eroded. The agro ecological zone of the area is semi-arid with savannah grassland vegetation. The County experiences low rainfall with a mean annual rain fall of $600 \mathrm{~mm}$. This affects availability of clean and safe water for domestic use.

The study targeted all households with children less than five years with mothers/caregivers living in the community as the main respondents.

Sample size was calculated using Cochran formula (Mugenda \& Mugenda, 2003).

No $=\frac{Z^{2} p q}{\mathrm{e}^{2}}$

No $=$ the desired sample size

$\mathrm{Z}=$ standard normal deviate taken at $95 \%$ confidence level (1.96)

$\mathrm{P}=$ proportion of the population with given characteristics which is 600

$\mathrm{e}=$ desired level of precision $(0.05)$

$\mathrm{q}=1-\mathrm{p}$; therefore

No $=(1.96)^{2}(0.5)(0.5)=384$

$(0.05)^{2}$

The sample size of 384 was adjusted to 422 by adding $10 \%$ of the population to cater for cases of nonresponse. Data is reported for 401 households. Data was collected using a semi-structured questionnaire.

Marigat division in Baringo County was purposively selected. The population was divided into 9 villages such that the focus was $422 / 9=47$ households. From each village, a list of all households with children underfive was generated by community health volunteers. Then, Systematic random sampling was used to select 47 households from the total censured. The total population was divided by 47 to get the $n$th term. Then the starting point was identified by use of table of random numbers. Thereafter, the households were selected.

A research-administered questionnaire was used for data collection on socio-demographic characteristics, water sources, water treatment and the prevalence of diarrhea. The tool was pre-tested on content, language and duration taken to administer. A sample of 40 respondents, which is $10 \%$ of the sample size under study was used for pretesting.

The laboratory water analysis from different sources and treatment methods was done to determine the level of $E$. coli. The water microbial load was determined before and after the treatment to check on the effectiveness of each treatment method. This was done by analyzing the concentration of viable $E$. coli in treated or stored water at the point of use in each household. Water quality classification was done according to the WHO guidelines (WHO 2011) for drinking water quality, which articulate E. coli risk levels as described in the Table 1.

Table 1: Risk classifications for $E$. coli most probable number (MPN)/100 mL

\section{WHO classification}

Safe/low risk

Questionable safety/intermediate risk

Unsafe/high risk

Unsafe/very high risk

The research assistants were first to explain the study objectives to the respondents. Questionnaires were administered after the informed consent was signed or a thumb print put.

On water collection procedure, water sample from different sources and treatment methods were collected. Thoroughly washed and sterilized Plastic kegs of 2 liters capacity were used to collect samples for laboratorybased experiments. Total coliforms and Escherichia coli (E. coli) were described under analytical methods of serial dilution using the plate method. MacConkey Broth (MB) was used as the culture medium in the presumptive test while Brilliant Green Lactose Bile Broth (BGLBB) was used as culture medium for the confirmed test. Exactly 0.1 milliliter of $10^{-4}$ dilution was plated on duplicate plates of plate count agar (PCA) and incubated at $30^{\circ} \mathrm{C}$ for 48 hours after which the total coliforms were enumerated. Coliform presence was determined by serial dilution. 1 milliliter of $10^{-4}$ dilution was added into $10 \mathrm{ml}$ of MacConkey media and 
incubated at $35^{\circ} \mathrm{C}$ for 24 hours after which the positive test tubes were determined. Positive test tubes were incubated in brilliant green media for 24 hours at $35^{\circ} \mathrm{C}$. Positive brilliant green samples were further incubated into EC broth at $45^{\circ} \mathrm{C}$ for 48 hours. Positive EC broths were incubated into Endo-agar at $35^{\circ} \mathrm{c}$ for 24 hours. Positive Endo-agar plates were incubated into Nutrient Agar at $35^{\circ} \mathrm{c}$ for 24 hours.

Completed questionnaires were checked, edited and coded before data entry. Data entry and analysis was done using SPSS software. Chi-square was used for categorical variables while Pearson's correlation coefficient was used for non-categorical variables to show the association between water safety practices and occurrence of diarrhea. Data analysis on E.coli concentration was recorded and then compared with the WHO guidelines for drinking water quality, which articulate E.coli risk levels.

\section{Results and discussion \\ Demographic characteristics}

Demographic characteristics: Out of the 422 targeted, 401 questionnaires were completed. The age and marital status of the mothers was assessed. Results show that the majority of mothers $(50.6 \%)$ were of age $26-35$ years. There was no significant difference $(\mathrm{p}>0.05)$ in the mothers various ages. Majority $(78.3 \%)$ of the mothers were married, though there were some who were unmarried (15.2\%) (Table 2). The study notes that majority of the respondents (46.9\%) had education up to primary level. About $26.7 \%$ completed secondary school while $12 \%$ had tertiary education. There was a significant difference $(\mathrm{p}=0.015)$ in the mothers in the various levels of education. Most of these mothers were either into farming or small businesses like retail shops, tailoring or selling of clothes as represented by $28.2 \%$ and $26.4 \%$, respectively. There was no significant difference $(p=0.131)$ in the mothers in respect to occupation. The socio-economic characteristics of the households is shown in Table 2. Findings from household income indicates that majority of households earns less than 10,000 KES with 5\% earning more than 50,000. There was a significant difference $(\mathrm{p}=0.004)$ in the household as pertains to income.

Table 2: Demographic characteristics of the caregivers

\begin{tabular}{llll}
\hline & & $\mathbf{n ~ ( 4 0 1 )}$ & $\mathbf{\%}$ \\
\hline Age & $16-25$ & 73 & 18.2 \\
& $26-35$ & 203 & 50.6 \\
Marital status & $36-45$ & 125 & 31.2 \\
& & 401 & 100.0 \\
& Marriage & 314 & 78.3 \\
Education level & Single & 61 & 15.2 \\
& Separated/ divorced & 26 & 6.5 \\
& Primary incomplete & & 5.2 \\
& Primary complete & 21 & 46.9 \\
Secondary incomplete & 188 & 26.7 \\
Secondary complete & 37 & 12.0 \\
Tertiary & 107 & 3.7 \\
& Housewife & 48 & 12.0 \\
& Casual labour & & 14.0 \\
& Pastoralism & 15 & 15.7 \\
& Civil servants & 48 & 26.4 \\
& Business & 56 & 28.2 \\
& Farming & 63 & 42.9 \\
& $<10,000$ & 106 & 35.1 \\
& $10,001-30,000$ & 113 & 17.0 \\
& $30,001-50,000$ & 172 & 5.0 \\
\hline
\end{tabular}

\section{Water sources}

Respondents were asked several questions related to their source of water and results recorded (Table 3). Most of the respondents $(50.6 \%)$ used river as their main source of water. However, a few $(31.2 \%$ and $18.2 \%)$ used borehole and rainwater respectively. These findings are similar to other studies that indicate that most of the rural households use river as the main source of water. Similar studies, one in western Kenya by Tenge et al. (2015), and another in Gatundu, Kiambu by Mensah, et al. (2015) also noted that most rural communities obtain water from the river. 
Table 3: Water sources

\begin{tabular}{lll}
\hline & n (401) & \% \\
\hline Rain Water & 73 & 18.2 \\
River & 203 & 50.6 \\
Borehole & 125 & 31.2 \\
\hline
\end{tabular}

\section{Water Safety/Microbial level}

The study further sought to establish the concentration of E.coli in water sources (river, borehole and rain water) at the household levels (Table 4). The study found that River was the most contaminated source of water (50 MPN/100 mL) which is unsafe for human consumption according to WHO classification. This findings correlate with Nollet, L.M et al (2000) who noted that river is the most contaminated source of water particularly in the developing world.

The study revealed that sources of water contamination include agricultural runoff as well as human fecal waste and animal waste. This concur with a study in informal settlements of Kisumu City, western Kenya by Opisa, S. et al (2012).

Table 4: Variation in MPN/100ml of $E$. coli presence in different water sources before treatment

$\begin{array}{ll}\text { Water Source } & \text { E. coli MPN/100 mL } \\ \text { River } & 50 \\ \text { Borehole } & 9 \\ \text { Rain Water } & 5\end{array}$

\section{Water Treatment}

The number of water treatment methods used at the household levels were determined (Table 5). Results show majority (37.2\%) used Moringa oleifera seeds which acts as a natural absorbent and antimicrobial agent. However, only a few (26.7\% and 9.7\%) used water guard and boiling respectively. Results show that $20.9 \%$ did not treat their water.

The use of Moringa oleifera seeds in water treatment (Table 5) in this study is in agreement with a study by Mangale, S. M. et al (2012) who also noted, Moringa oleifera (drumstick) seed as natural absorbent and antimicrobial agent for water treatment. Other studies that show use of natural coagulant are by Mumbi, A. W. et al (2018). Households have been shown to use natural coagulant in water treatment due to its economical availability. A study by Yin, C. Y. (2010) also came up with such findings.

Table 5: Distribution of the households by mode of water treatment

\begin{tabular}{lll}
\hline & $\mathbf{N}(\mathbf{4 0 1})$ & $\mathbf{\%}$ \\
\hline Moringa oleifera seeds & 149 & 37.2 \\
Water guard & 107 & 26.7 \\
No method used & 84 & 20.9 \\
Boiling & 39 & 9.7 \\
Filtration & 22 & 5.5 \\
\hline
\end{tabular}

Table 6: Variation in MPN/100ml of $E$. coli presence in different water treatment methods after treatment

\begin{tabular}{ll}
\hline Treatment Method & E. coli $\mathbf{M P N} / \mathbf{1 0 0} \mathbf{~ m L}$ \\
Moringa Oleifera Seeds & 3 \\
Boilling & 8 \\
Water guard & 8 \\
Decantation and filtration & 30 \\
\hline
\end{tabular}

Relationships between water safety practices and occurrence of diarrhea

The prevalence of diarrheal was $57.6 \%$ as shown in Figure 1. The relationships between the study variables is as shown in Table 7 . This was by use of chi-square for categorical variables and person correlation for noncategorical variables.

Table 7: Relationship between study variables.

\section{Relationship}

between water safety practices and other variables

$\begin{array}{ll}\text { Variable } & \text { Statistics } \\ \text { Diarrhea present } & \mathrm{r}=0.643 ; \mathrm{p}=0.017 \\ \text { Age } & \mathrm{r}=0.153 ; \mathrm{p}=0.085 \\ \text { Marital status } & \chi 2=121 \mathrm{df}=6, \mathrm{P}=<0.001 \\ \text { Education level } & \chi^{2}=121 \mathrm{df}=6, \mathrm{P}=<0.001 \\ \text { Household income } & \mathrm{r}=0.524 ; \mathrm{p}=0.008\end{array}$

There was a significant relationship $(\mathrm{P}<0.05)$ between the water safety practices and occurrence of diarrhea. 
Other studies have found the same association. Poor water safety practices were found to lead to high prevalence of diarrhea. A study by Hasanain, F. G. et al. (2012) found a significant relationship between drinking water sources and diarrhea. The results also are similar to a study by De Ver Dye, T. et al. (2011) on water safety practices which found out that use of water filters and use of clean water, reduced occurrence of diarrhea diseases. These findings are in line with a systematic review of the health outcomes related to household water quality in developing countries by Gundry, S. et al (2004). A study by Halvorson, S. J. et al (2011) elaborates on how drinking water supplies, sanitation, hygiene, household water treatment plays an important role in the reduction of diarrheal diseases

In addition, the education level, income and marital status are significantly $(\mathrm{p}<0.05)$ related with the water safety practices. Age in this study was not an important predictor of water safety practices. A study by Bennett, S. D. et al (2018) in Malawi found that education, occupation and income affected the occurrence of diarrhea. A study by Halvorson, S. J. et al (2011) elaborates on how marital status and education affect occurrence of diarrhea.

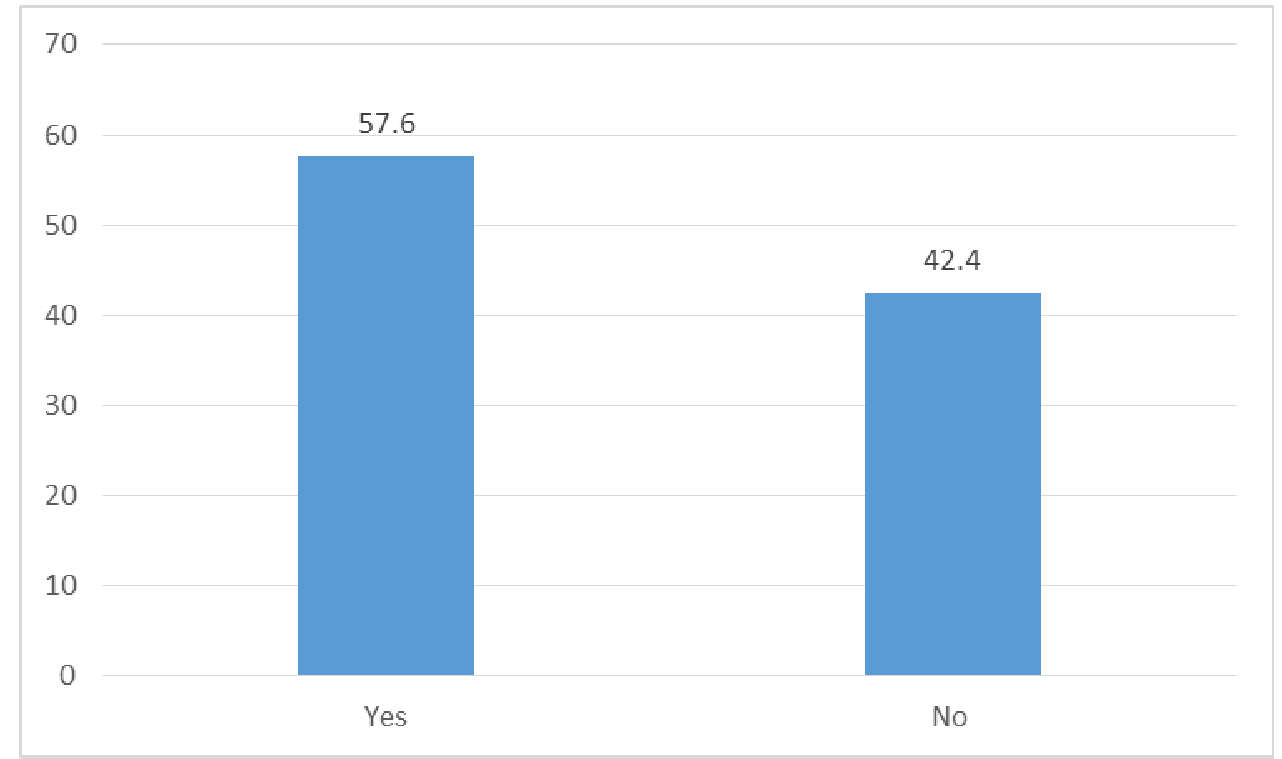

Figure 1: Presence of diarrhea among children under five

\section{Conclusion}

This study noted that water safety practices of the Njemp community was poor. It also reports increased diarrhea cases among the children under five years. This is because most of them obtained water from the river which had E.coli concentration above the recommended level. As such some of them did not treat their water and this consequently led to increased diarrhea cases. The lack of water treatment was attributed to low education level and this consequently led to adoption of low profile careers like casual labor and pastoralism. This resulted to low income which was barely enough to dig boreholes, have piped water, procure water guard or adopt modern methods of water treatment. The low education level and low income translated to poor decision making in water sources and treatment methods resulting to increased cases of diarrhea. The determinants of diarrhea occurrence among children below five years are water safety practices, water source, water treatment, education level and income.

To increase access to clean and safe water among the households, the County government of Baringo, should come up with a centralized water treatment plant or dig boreholes and sell the water to the people in Baringo County at subsidized prices. Need for training on the importance of water treatment using cheap and affordable traditional methods

\section{References}

Baum, R., Kayser, G., Stauber, C., \& Sobsey, M. (2014). Assessing the microbial quality of improved drinking water sources: results from the Dominican Republic. The American journal of tropical medicine and hygiene, 90(1), 121-123.

Bennett, S. D., Lowther, S. A., Chingoli, F., Chilima, B., Kabuluzi, S., Ayers, T. L., ... \& Mintz, E. (2018). Assessment of water, sanitation and hygiene interventions in response to an outbreak of typhoid fever in Neno District, Malawi. PloS one, 13(2), e0193348.

De Ver Dye, T., Apondi, R., Lugada, E., Kahn, J. G., Sandiford-Day, M. A., \& DasBanerjee, T. (2011). A qualitative assessment of beliefs, attitudes, and behaviors related to diarrhea and water filtration in rural 
Kenya. American journal of public health, 101(8), 1515-1520.

Gundry, S., Wright, J., \& Conroy, R. (2004). A systematic review of the health outcomes related to household water quality in developing countries. Journal of water and health, 2(1), 1-13.

Halvorson, S. J., Williams, A. L., Ba, S., \& Dunkel, F. V. (2011). Water quality and waterborne disease in the Niger River Inland Delta, Mali: a study of local knowledge and response. Health \& place, 17(2), 449-457.

Hasanain, F. G., Jamsiah, M., Zaleha, M. I., \& Azmi MTamil, M. A. (2012). Association between drinking water sources and diarrhea with malnutrition among kindergarten's children in Baghdad city, Iraq. Malays J Public Health Med, 12(1), 45-8.

LeeE. J.SchwabK. J. 2005 Deficiencies in drinking water distribution systems in developing countries. J. Water Health 3 (2), 109-127.

Liu L., Oza S., Hogan D., Perin J., Rudan I., Lawn J.E., Cousens S., Mathers C., Black R.E. Global, regional, and national causes of child mortality in 2000-2013, with projections to inform post-2015 priorities: An updated systematic analysis. Lancet. 2015; 385:430-440. doi: 10.1016/S0140-6736(14)61698-6

Mangale, S. M., Chonde, S. G., Jadhav, A. S., \& Raut, P. D. (2012). Study of Moringa oleifera (drumstick) seed as natural absorbent and antimicrobial agent for river water treatment. J Nat Prod Plant Resour, 2(1), 89-100.

Mensah, A. K., Kissi, E. A., Krah, K., \& Mireku, O. D. (2015). The extent of groundwater use for domestic and irrigation activities in Thiririka sub-catchment, Gatundu South District, Kiambu County, Kenya. African Journal of Environmental Science and Technology, 9(6), 519-530.

Mumbi, A. W., Fengting, L., \& Karanja, A. (2018). Sustainable treatment of drinking water using natural coagulants in developing countries: A case of informal settlements in Kenya. Water Utility Journal, 18, 111.

Nollet, L. M., \& De Gelder, L. S. (Eds.). (2000). Handbook of water analysis. CRC press.

Opisa, S., Odiere, M. R., Jura, W. G., Karanja, D., \& Mwinzi, P. N. (2012). Faecal contamination of public water sources in informal settlements of Kisumu City, western Kenya. Water Science and Technology, 66(12), 2674-2681.

ProkopyL.ThorstenR.BakalianA.WakemanW. 2008 Evaluating the role of postconstruction support in sustaining drinking water projects evidence from Peru. J. Plann. Educ. Res. 27 (3), 294-305.

RellerM. E.MendozaC. E.LopezM. B.AlvarezM.HoekstraR. M.OlsonC.LubyS. P. 2003 A randomized controlled trial of household-based flocculant-disinfectant drinking water treatment for diarrhea prevention in rural Guatemala. Am. J. Trop. Med. Hyg. 69 (4), 411-419.

Sharma NP et al. (1996) African Water Resources: Challenges and Opportunities for Sustainable Development. World Bank Technical Paper no. \#331. Africa Technical Department Series, Washington.

Tenge, J. M., Lusweti, J. K., \& Ng'wena, G. A. M. (2015). Assessment of Drinking Water Quality from the Malakisi River in Western Kenya. International Journal of Innovative Research \& Development, 4(4), 154 161.

UNICEF \& WHO 2013 Progress on Drinking Water and Sanitation 2012 Update (pp. 1-59). New York. www.wssinfo.org/.

UNICEF \& WHO 2014 Progress on Drinking Water and Sanitation 2014 Update (pp. 1-25). http://www.wssinfo.org/fileadmin/user_upload/resources/JMP-report2014Table_Final.pdf.

United Nations 2012 Indicators for Monitoring the Millennium Development Goals: Definitions, Rationale, Concepts and Sources. http://mdgs.un.org/unsd/mi/wiki/7-8-Proportion-of-population-using-an-improveddrinking-water-source.ashx.

WHO/UNICEF. Progress on Sanitation and Drinking Water: 2015 Update and MDG Assessment. WHO; Geneva, Switzerland: 2015.

World Health Organization (WHO) and United Nations Children's Fund (UNICEF) Joint Monitoring Programme for Water Supply and Sanitation 2000; Progress in Drinking Water and Sanitation with focus on sanitation. UNICEF New York and WHO Geneva.

World Health Organization 2011 Guidelines for Drinking-water Quality, 4th edn. World Health Organization, Geneva, Switzerland.

Yin, C. Y. (2010). Emerging usage of plant-based coagulants for water and wastewater treatment. Process Biochemistry, 45(9), 1437-1444. 